\title{
Reply to the Kyle Swan Review of Escape from Leviathan
}

\section{J. C. Lester}

The central classical liberal insight is that private property appears both to protect personal liberty and to promote general productivity. By way of philosophically clarifying this insight, Escape from Leviathan (EfL) posits the extreme classical liberal, or libertarian, Compatibility Thesis: there is no long-term, systemic, practical conflict among economic rationality, interpersonal liberty, human welfare, and private-property anarchy (i.e., four plausible and relevant theories ${ }^{1}$ of these that are presupposed, or entailed, by libertarianism and consonant social science). The review (Liberty, November 2002) holds that this extreme version is probably false and suggests that perhaps even EfL's author would agree. He (still) does not, although he remains open to argument. But what anyone happens to believe at any particular moment is a piece of fleeting biography that is irrelevant to the truth of the thesis or the soundness of the arguments in EfL.

As the review explains, EfL uses the critical rationalist epistemology of seeking tests or criticisms for its conjectures (which include conjectural explanations) instead of trying to support them. The review questions whether this "is the best we can do". It says, "I don't see why there can't be a transfer of justification between two propositions, one of which is grounded in the other". But how is the first one "grounded"? The review observes that Loren Lomasky sees libertarianism as having "its foundation in a particular theory of practical reason". It's not possible to deal properly with this brief suggestion here beyond noting that deeper levels of theory are not thereby a "foundation" in any epistemologically supporting sense. They are merely more basic conjectures. It's conjectures all the way down. Hence there is no ultimate support.

It is a partial truth at best that, as the review notes, making "ideas logically compatible with each other doesn't have to be especially difficult". It depends on how precise the original ideas are or whether mere placeholder words are all that is really meant by "ideas". EfL is engaged not only in making all four conceptions individually and collectively coherent but also plausibly accurate interpretations that are able to deal with independent criticisms, or different interpretations, and to solve various problems. Thus, it is explaining and defending appropriate theories of each conception. It is not 'defining ideas' so that the mere words are trivially consistent. The theories have to make substantive and defensible sense of the classical liberal insight and the extreme version being defended.

The review jumps to free will with the assertion that "the conception that a free will is one that is not determined by anything external to the agent isn't compatible with determinism". But assuming determinism and then saying that an agent's will is still free as long as it is not determined by anything external to that agent just is the traditional compatibilist view. It appears to be coherent: he did action $\mathrm{X}$ because he wanted to do action $\mathrm{X}$ - even if this will arose from deterministic factors within his brain - and not because external forces were somehow controlling him like a puppet. Perhaps the review implicitly conceives of an "agent" as being only an abstract mind (in which case perhaps even every part of the brain is "external" to it) rather than a kind of biological entity (as EfL assumes).

However, the review then offers a conception of free will that appears to be along the lines defended in EfL and compatible with determinism: "one's will is free so long as it isn't interfered with, or compelled, by others". But as Thomas Hobbes would have observed, even when we obey at gunpoint we still make a free-will choice, albeit under the perceived constrained circumstances. The review, again, objects that "it may be very easy to make a set of terms logically compatible with each other simply by defining the terms in such a way that they don't conflict". And, again, EfL does not do this. Here it defends a compatibilist theory of free will from criticism and argues that the other theories are false. One cannot validly reject the explanatory arguments, as the review implicitly or in effect does here, on the assumption that the mere consistency of the "terms" indicates that they must really be only fiddled definitions (one might say the same of the "terms" within any scientific theory). It might equally well be countered that "it may be very easy to make a set of terms logically incompatible with each

\footnotetext{
${ }^{1}$ Unfortunately, EfL often slips into referring to its conceptions or theories as 'definitions'; and this has sometimes caused confusion (although a theory can also be used as a definition). 'Definitions' are about explaining words while 'theories' are about explaining the world (including the world of abstractions, such as the abstract conception of liberty that libertarianism entails). For greater clarity, the distinction is observed here.
} 
other simply by redefining the terms in such a way that they do conflict'. That said, it ought to be noted that the truth or falsity of the compatibility of free will and determinism is not at all crucial to the Compatibility Thesis of $E f L$ - metaphysical free will could do the job too- but it was necessary to give some coherent account of this that fitted with the theory of rationality.

The review then offers two explicit objections to the Compatibility Thesis: "First, I think that either the four ideas are not strictly compatible, or, if they are, the compatible thesis becomes somewhat trivial. Secondly, I disagree flat-out with one of Lester's definitions". But EfL does not assert that the "four ideas" are "strictly compatible"; it only claims that there is no long-term, systemic, practical conflict among them. And that does not appear to be "trivial" but a real conjectural explanation of the social science that is in favour of the classical liberal insight. Again, these "ideas" are not "definitions" but relevant theories; and which one the review rejects "flat-out", and for what reason, is not specified. But let us see whether any further explanations of these objections withstand examination.

The review cites "the issue raised by David Friedman that 'turning on a light or striking a match can send photons onto the property of others, so, given absolute property rights, one cannot even do such trivial things without the permission of everyone affected' (73)". The review says that "a theorist seems forced to choose between an individual's absolute control of property and perfect liberty. The choice Lester apparently prefers is to give up perfect liberty". Here the review is simply mistaken. EfL argues that neither of these is possible. And libertarians would not be libertarians if they were not for liberty, although perhaps only for as much liberty as is practical. The review asserts that "Lester admits the possibility of cases where his definition of liberty conflicts with his definition of private property". But there is no clash with respect to "definition". Because of inescapable practical clashes in initiated impositions, perfect liberty is not always possible. However, liberty-derived private property is usually a way of minimising such clashes.

The review continues that "it would not be difficult to imagine cases in which liberty would also conflict with people's having their unimposed wants satisfied". But merely "to imagine cases" is not a problem for the long-term, systemic, practical claim of the Compatibility Thesis. EfL does not in any way "retreat" from its theory of 'liberty-in-itself' as 'people not having a subjective cost initiated and imposed on them by other people' (or 'no initiated impositions', for short). Such liberty is maximised where welfare (want-satisfaction) is maximised and appropriate private property is maximised (briefly, because libertarian-derived private property inherently maximally internalises initiated imposed externalities and is thereby maximally economically efficient). Hence these things do not significantly and systemically conflict in practice. EfL does not assert that we can always have perfect liberty, perfect welfare, and perfect private property.

The review asks, "What will determine in these cases the extent to which impositions will be permitted?" The answer in realistic cases, at least (rather than cases that the review can "imagine"), is that, in principle, overall initiated impositions need to be minimised by whatever means does this best (usually by appropriate private-property rules and remedies). The review incorrectly supposes that "where the perceived conflict is between individual liberty and private property, it will be just those impositions that are compatible with protecting another's property". No, it will be whatever maximises liberty (i.e., minimises overall initiated impositions). Has the review overlooked that EfL derives property rights, including self-ownership, by applying the theory of interpersonal liberty? Liberty-initself is not theorised in terms of property; and subsequently derived private property is only a strong rule of thumb as regards liberty-in-practice - it can never trump liberty.

On perpetual copyrights (as long as they are not eventually abandoned, at least), the review suggests that this will sometimes impose costs on those who do not own them, "even those who, for example, won the race to the idea, but lost the race to the copyright office, or arrived at the idea later than, but independently of, the copyright holder". This seems to be confusing copyrights and patents. At the extreme, copyrightable innovations are not likely to be thought of independently ("I wrote an identical Hamlet before I knew of Shakespeare's play"?). It is also conflating criticism of the abstract theory with criticism concerning a possible practical difficulty. EfL discusses various problems and solutions with respect to each. Strictly, it does not recognise absolutely distinct categories of intellectual property but envisions a spectrum of intellectual innovations ranging from those that might, otherwise, be independently created very soon afterwards (e.g., some inventions and pharmaceuticals, also maps and mathematical tables) to those that it is implausible would ever be independently created (e.g., novels 
and symphonies). ${ }^{2}$ It is hard to see what the review finds problematic with this, so it would not be useful to say more here.

Of the overall Compatibility Thesis, the review asserts that the "bold conjecture [...] is weakened to the more judicious claim that liberty must be compromised in order to secure strong property rights". This is wrong in two crucial ways. Overall liberty is never "compromised": libertarians, qua libertarians, must opt for the maximum liberty possible; and perfect liberty might not always be possible. And EfL clearly takes the position that private property, whether as normally conceived or even as derived from its own abstract theory of liberty-in-itself, does have to be modified when it clashes with maximising liberty. For example, contra Rothbard, EfL argues that the person who finds himself surrounded by someone else's property must be allowed reasonable easements, although perhaps with some compensation payable, as that is a lesser initiated imposition on the other owner than allowing his imprisonment would be on him.

The review then asks, "Who would deny that private property is compatible with as much individual liberty as is attainable when perfect liberty (as Lester defines it) is unattainable?" Just about everyone who is not a libertarian might well deny this (even when accepting liberty as EfL theorises it). $E f L$ does not mean to argue only with libertarians. But even EfL only holds libertarian private property as a strong general rule: problematic cases can entail applying abstract liberty-in-itself and remedies for clashes that override normal private property (e.g., 'trespass' is allowable when it is necessary to escape some disaster or a dangerous pursuer: the landowner did not, typically, create the land itself across which the trespasser needs to flee). The review says that EfL's choice is for "allowing the protection of private property to condition the 'amount' of individual liberty". This is the reverse of the truth. This sounds like an implication of some non-libertarian conception of liberty. How does the protection of private property overall limit liberty (except in special cases where, as just explained, it can be overridden) when private property is derived from applying abstract liberty-in-itself? Patents are then put forward as an example of EfL doing the opposite, and right, thing. But EfL explains how patents (being usually independently creatable, or discoverable, given time) differ from copyrights in applying the theory of liberty. What is wrong with the explanation? How is only this putting liberty first?

The aprioristic "definition" (theory) of rationality is asserted to be "implausible": that 'agents always attempt to achieve what they most want under the perceived circumstances'. The review holds this implausible because of the possibility of false beliefs. If I mistake a glass of gasoline for a glass of juice, I do not have an "objective reason" to drink it "but I would have been attempting to achieve what I most wanted under the perceived circumstances". Exactly what the theoretical problem is supposed to be here is not at all clear. But, yes, people can make mistakes. EfL is defending a theory of subjective rationality. Why should it be defending an "objective" (perfect?) theory instead? There is nothing inherently wrong with objective theories, as such; they are simply peripheral, at best, to explaining the real values, choices, and actions of agents (and the review's version looks more like an unattainable perfect prudence than a theory of rationality). Does the review imply that EfL's subjective theory will somehow lead to mistaken gasoline-drinking in practice? EfL does also argue that it is overall welfareenhancing — so would also, perhaps, thereby be overall 'objectively rational' for the review - to allow people to learn from their own mistakes. Readers of EfL are then referred to the literature on what happens when 'experts' are empowered to choose for them. Is there something faulty with that? ${ }^{3}$

All that said, an extremely concise and much more comprehensible explanation of EfL's general theory of libertarian philosophy can now be found in one short essay, ${ }^{4}$ and in more detail in a somewhat

\footnotetext{
${ }^{2}$ Mark Brady helpfully clarified the position on intellectual property taken in $E f L$, and here offered a reminder of what that is.

${ }^{3}$ For a detailed defence of this theory of rationality from sustained criticism see Lester, J. C. "Adversus 'Adversus Homo Economicus': Critique of the 'Critique of Lester's Account of Instrumental Rationality"' (https://philpapers.org/rec/LESAAH-2).

4 Lester, J. C. 2022. "Eleutheric-Conjectural Libertarianism: a Concise Philosophical Explanation" (https://philpapers.org/rec/INDNLA).
} 
longer one. ${ }^{5}$ There are also further elaborations and defences in two more books. ${ }^{6}$ But both these essays and these books omit many of the details and additional issues to be found in EfL, which still forms part of a more comprehensive account-albeit far more complicated and often far less clear (first explanations of unorthodox theories are usually much improved by criticism).

(October 2002; revised January 2022.)

${ }^{5}$ Lester, J. C. "The Heterodox 'Fourth Paradigm' of Libertarianism: an Abstract Eleutherology plus Critical Rationalism." Journal of Libertarian Studies, 23:91-116 (2019).

${ }^{6}$ See relevant chapters in Lester, J. C. Explaining Libertarianism: Some Philosophical Arguments (Buckingham: The University of Buckingham Press, 2014) and, to a lesser extent, Arguments for Liberty: A Libertarian Miscellany (Buckingham: The University of Buckingham Press, 2014). 